\title{
EFICÁCIA DO TINIDAZOL NO TRATAMENTO DA GIARDÍASE
}

\author{
Vicente Amato Neto **, Guido Carlos Levi ***, Sélia Reiko Konichi *** \\ e Lúcia Lacerda Campos ****
}

\begin{abstract}
Utilizando o tinidazol, tratcram os autores 30 individuos adultos infetados pela Giardia lamblia. Administraram uma drágea de $150 \mathrm{mg}$ duas vezes em 24 horas, durante sete dirs consecutivos.

Constataram a percentagem de curas de $93.3 \%$ sendo que a tolerância ao medicamento usado foi, em geral, muito satisfatória.

Em face aos resultados obtidos, salientaram que, sem dúvida, a droga antiparatitária empregada, de advento recente e atualmente submetido a múltiplas investigações de caráter terapêutico, representa eficiente recurso capaz de debelar a injecção motivada pela Giardia lamblia. Além aisso, consideraram conveniente, depois da pesquisa efetuada, procurar estabelecer esquemas posologicos dotados de virtudes ainda mais destacáveis.
\end{abstract}

\section{INTRODUC̣ĀO}

Felizmente, nos últimos anos, tornaram-se disponíveis medicamentos altamente efetivos no sentido de propiciar a cura da infecção devida à Giardia lamblia. Entre êles, a furazolidona e o metronidazol ccupam posição de destaque e têm merecido ampla utilização.

Outra droga capaz de beneficiar pacientes com giardíase é a nitrimidazina, conforme destacaram recentemente Levi \&cols. (4).

Levando em conta que a protozoose em apreço é muito disseminada e acomete elevados números de pessoas, afigura-se compreensivel a conveniência de dar prosseguimento às investigaçōes de caráter terapêtico com ela relacionadas. De tais estudos poderão decorrer deduções eventual- mente úteis sob o ponto de vista prático, envelvendo prcgressos pertinentes a custos mencs elevados, planos posológicos mais singelos e melhores tolerâncias por parte dos dcentes, entre outros.

C tinidazol ou etil 2-(2-metil-5-nitro-1imidazolel) etil-sulfona, de acordo com Howes Jr. \& cols. (3), Miller \& cols. (5) e Taylor Jr. \& cols. (6), é possuidor, "in vivc." e "in vitro", de notória capacidade antiparasitária, no que concerne a diversas modalidades de protozoários. Quanto à tricomoníase genital humana, marcante ação curativa ficou comprovada, circunstância que aliada aos fatos antes expostos $\epsilon$ à característica química do composto, motivaram o nosso interesse de avaliar a aventual capacidade, a ele inerente, de eliminar os acometimentos determinados pela Giardia lamblia.

* Trabalho do Serviço de Doenças Transmissiyeis do Hospital do Servidor Publico Estadual "Francisco Morato de Oliveira" e da Seçâo de Paraeitologia do Institulo Adolfo Lutz. de Săo Paulo.

* Diretor do Servico de Doenças Transmissiveis.

*** Medico do Servico de Doenças Transmissiveis.

**** Técnica de laboratório da Seção de Parasitologia.

Recebido para publicacào em $16.5,1972$ 


\section{MATERIAL E METODOS}

Trinta individuos adultos, de ambos os sexos, com glardiase pouco tempo antes diagnosticada através de exame parasitológico das fezes, receberam uma drágea com $150 \mathrm{gm}$ de tinidazol duas vezes em 24 horas, durante sete dias consecutivos. Tais pesscas residiam em um conjunto de habitaçōes rústicas situado na serra do Mar, conhecido como "cota 200" e localizado no município de Cubatão. às margens da Via Anchieta.

Baseamos o controle de cura na execução de três exames da matéria fecal, 7, 14 e 21 dias após o término da série medicamentosa. O método laboratorial empregado foi o de Hoffman, Pons e Janer. sende que detalhes pertinentes a esse processo estão consignados no compéndio especializado de autoria de Amato Neto \& cols. (1). Consideramos que houve eliminação da parasitose quando as pesquisas semanais citadas não evidenciaram cistos de Giardia lamblia.

Desaccnselhamos a ingestāo de bebidas alccólicas durante c período de tratamento e, por prudência, na casuística nāo estavam incluidas mulheres grávidas.

\section{RESULTADOS}

Apenas dois insucessos fjcaram constatados e, portanto, pudemos estabelecer a percentagem de curas de $93,3 \%$.

Manifestaçōes secundárias, atribuidas ao tinidazol, foram incomuns. Um paciente queixou-se de discreta cefaléia e, outro, de scnolència, presente só na fase terapêutica inicial. E interessante frisar que um dos constituintes da casuistica, acometido de intensa cefaléia, dor abdominal e diarréia, interrompeu o uso da droga no quarto dia e, mesmo assim, evoluiu no sentido de cura parasitológica.

\section{CCMFNTÁRIOS}

Cs fatos relatados, permitem, acreditamos, apresentar as ponderacōes a seguir enumeradas.
1) A investigaçāo empreendida deixou patente que o tinidazol é destacadamente eficiente quando administrado com o intuito de debelar a giardiase.

2) A taxa de êxitos terapêuticos assinalada, bastante significativa, permite situar a droga em auestãc entre as mais efetivas, quando a eliminação do parasitismo causadc pela Giardia lomblia é o objeivo visado.

31 Levamos a cabo o estudo em ambiente rural onde a protozoose é muito comum; essa circunstância, somada à fácil transmissão do processo mórbido parasitáric, nele provavelmente vigente, concedem maior interesse ao resultado global detectado.

4) A tclerância, em geral muito satisfatória, ao agente antiparasitário, é particularidade também digna de destaque, pois constitui atributo indispensável de remédic destinado a bencficiar grandes númeres de pessoas.

5) Tivemos noticia, por meio de relatório mimeografado e nào publicado, que Andersson \& cols. (2) chegaram à conciusãc ainda mais convincente do que a por nós já indicada, uma vez aue curaram todos os estudantes tratados, prescrevendo posologia igual à escolhida na presente pesquisa. Curiosamente, contaram que muitos componentes de um grupo de suecos que visitaram Leningrado, na Rússia. foram infetados pela Giordin lamblin e cassaram a cofrer de marcantes distúrbios referentes ac aparelho digestivo. O tinidazcl mostrou-se muito valioso quando escothido como recurso terapêtico, pois conduziu a èxitos, sob os pontos de vista clinico e parasitológico.

Essa referência e as nossas deducões sāo as únicas documentaçōes disponiveis a respeito dessa virtude terapêutica imputável ac novo composto. Daqui para diante será preciso, logicamente, analisar as qualidades de outros esauemas e dosagens, para eventualmente simplificar condutas rotineiras.

\section{AGRADECIMENTOS}

Pelo fornecimento do tinidazol utilizado na presente investigacão, consignamos cs nossos agradecimentos à firma "Pfizer Química Ltda,". 


\section{SUMMARY}

Treating 30 adult patients bearers of Giardia lamblia injection with tinidazole at a dosage of $150 \mathrm{mg}$. twice a day for seven consecutive days, the authors have obtained a cure rate of $93.3 \%$. The tolerance to the drug was, generally, very satisfactory.

In view of the results obtained, the authors pointed out that there is no question about being the drug used - a new antipasasitic which is under inany therapeutic trials at present - a most useful tool in treatment of infections caused by Giardia lamblia. After this investigation was carried out. the authors also considered it timely to establish new dosage schedules in order to obtain even better results.

\section{REFERENCIAS BIBLIOGRÁFICAS}

1. AMATO NETO, V., CAMPOS, R. \& SANTOS FERREIRA, C. - Diagnóstico das parasitoses intestinais pelo exame das fezes. São Paulo, Livraria Atheneu Editora S. Paulo S.A., 2" edição, 122 pp. 1963.

2. ANDERSSON, T. \& cols. - Fasigyn in the treatment of Giardia lamblia. Relatório fornecido à firma "Pfizer Química Ltda.".

3. HOWES JR., H. L., LYNCH, J. E. \& KIVLIN, J. L. - Tinidazole, a new antiprtozoal agent: effect en Trichomonas and other protozoa. Antimicrob. Agents Chemoter. - 1969: 261-266, 1970.
4. LEVI, G. C., AMATO NETO, V. \& CAMPOS, L. L. - Observações sobre o tratamento da giardiase de crianças, por meio da nitrimidazina. - Em publicação (Rev. Soc. Bras. Med. Trop.).

5. MILLER, M. W., HOWES, H. L. \& ENGLISH, A. R. - Tinidazole, a potent new antiprotozoal agent. Antimicrob. Agents Chemoter. - 1969: 257-269, 1970.

6. TAYLOR JR., J. A., MIGLIARDI, J. R. \& VON WITTENAU, M. S. - Tinidazole and metronidazole pharmocokinetics in man and mouse. Antimicrob. Agents Chemoter. - 1969: 267-270, 1970. 